\title{
CRIANÇAS E MÍDIAS: TRÊS POLÊMICAS E DESAFIOS CONTEMPORÂNEOS
}

\author{
CHILDREN AND MEDIA: THREE CONTEMPORARY \\ POLEMICAL ISSUES AND CHALLENGES
}

\author{
Gilka Girardello ${ }^{1, *}$ \\ Monica Fantin ${ }^{1}$ (D) \\ Rogério Santos Pereira ${ }^{1}$
}

\begin{abstract}
RESUMO: $\mathrm{O}$ artigo trata de três temas polêmicos nas atuais discussões sobre a vida das crianças na cultura digital: a mediação adulta ao uso das telas pelas crianças; a necessidade de formar as crianças para lidar com a desinformação em massa, revalorizando a dimensão crítica da mídia-educação; e o lugar reservado à corporeidade das crianças em uma sociedade atravessada pelo digital. Sugerem-se perspectivas teórico-metodológicas que possam contribuir para qualificar o debate social e as pesquisas sobre a relação entre as crianças e as mídias.
\end{abstract}

Palavras-chave: Mídia-educação. Crianças. Cultura digital. Crítica. Corporeidade.

ABSTRACT: This article addresses three of the most polemical issues in current discussions about children's lives in digital culture: adult mediation of screens used by children; the need to prepare children to deal with mass disinformation, revaluing the critical dimension of media-education; and the place reserved for children's corporality in a digitally permeated society. The discussion suggests some theoretical-methodological perspectives that can help qualify the social debate, and contribute to studies about the relationship between children and the media.

Keywords: Media education. Children. Digital culture. Critical. Corporality.

\footnotetext{
1.Universidade Federal de Santa Catarina - Programa de Pós-graduação em Educação - Florianópolis (SC), Brasil.

*Autora correspondente: gilkagirardello@gmail.com

Número temático organizado por: Gilka Girardello, Adriana Hoffmann e Inês Vitorino Sampaio
} 


\section{Introdução}

A relação das crianças com os artefatos culturais é um tema desafiador e historicamente atravessado por polêmicas, pois as sociedades tendem a projetar nas crianças as contradições de seus próprios temores e esperanças. Se, ao longo do século XX, sucederam-se no debate público as vozes contrárias e favoráveis a que crianças lessem histórias em quadrinhos, assistissem à televisão e usassem o computador, avançamos pelo segundo milênio com algumas questões novas - ou nem tão novas, porém reconfiguradas, mais uma vez, de forma polêmica. Neste artigo, situaremos três dos temas que consideramos mais candentes nas atuais discussões sobre a vida das crianças na cultura digital, a partir da maneira como esses temas se expressam no debate contemporâneo, buscando apoio em reflexões acadêmicas atuais que ajudem a levar o debate para além do senso comum. Trazemos também algumas considerações que emergiram do contexto da pandemia de 2020 e tornaram ainda mais agudas tais questões.

Um desses temas é a mediação adulta ao uso das telas pelas crianças: quanto tempo, em que idade e em que condições seria recomendável o convívio das crianças com os dispositivos eletrônicos? Um segundo tema desafiador é a presença das fake news nas redes sociais digitais e o quanto esse fato exige uma revalorização da dimensão crítica na mídia-educação. O terceiro, por fim, diz respeito ao lugar reservado à corporeidade das crianças em uma sociedade atravessada pelo digital. No artigo, a polêmica em torno desses três eixos será caracterizada com o auxílio de materiais extraídos do debate social corrente, como reportagens e manifestos, os quais discutiremos a partir de perspectivas teóricas que nos parecem oportunas e iluminadoras.

Nessa perspectiva, os temas se articulam a partir das relações entre crianças, mídias e tecnologias - relações essas mediadas pelos adultos de forma capacitadora ou limitadora. Assim, os argumentos dos três eixos encadeados no texto, marcados por polêmicas no debate público, interpelam os educadores com questões que assumem uma gravidade ainda maior no contexto da pandemia da Covid-19: quanto ao acesso aos artefatos digitais e à qualidade de conexão; quanto ao papel das diferentes mídias e das especificidades das redes sociais que repercutem diretamente nos usos das tecnologias por crianças; e quanto às mediações adultas e à corporeidade das crianças, especialmente em um momento em que o distanciamento social no contexto da pandemia modificou radicalmente a relação da criança com os pares, com os outros e com as tecnologias.

\section{Usos das Tecnologias Digitais entre Crianças}

O primeiro tema polêmico que iremos abordar é o dos usos das tecnologias digitais entre crianças, buscando fugir tanto da supervalorização da tecnologia quanto de sua subvalorização. O debate sobre esse assunto tem aparecido, nos últimos dois anos, em jornais, revistas, sites, conversas cotidianas, pesquisas acadêmicas e até mesmo em políticas públicas e documentos oficiais: "É hora de desligar o celular"1; “"As redes sociais estão dilacerando a sociedade', diz um ex-executivo do Facebook"2; "Odeio o celular da minha mãe, porque ela sempre está com ele: Uma professora publica o comentário de um aluno de sete anos e abre o debate sobre o uso dos celulares e o tempo de qualidade com os filhos ${ }^{3}$; "Não quero meu sobrinho nas redes sociais', diz Tim Cook, CEO da Apple”; “"Estamos criando uma geração de alienados', afirma psicólogo do Hospital das Clínicas de São Paulo. 'Jamais a gente deveria permitir o contato de uma criança com qualquer tipo de tecnologia antes dos 2 ou 3 anos de idade"'5; "Os gurus digitais criam os filhos sem telas": no Vale do Silício proliferam escolas sem tablets nem computadores e jardins da infância onde o celular é proibido por contrato ${ }^{6}$. 
Em tais matérias, é possível observar argumentos de familiares e especialistas do campo da psicologia, da medicina e da educação. Um psicólogo, por exemplo, relata seu espanto diante de conversas de mães que ele escuta no hospital onde trabalha: "Meu filho tem dois aninhos e já sabe mexer no celular e no tablet! É tão bonitinho!” Ele prossegue: “Dia desses chegou uma senhora no consultório dizendo que o filho não saía mais do celular. Fiquei pensando quantos anos tinha esse menino, 8 anos, 9 anos? Ela contava que, quando ele acorda, quer o celular, não almoça se não tiver o celular ao lado, não vai pra cama sem o aparelho. 'Mas qual idade têm seu filho?', perguntei. E ela me contou que o menino tinha apenas 2 anos e 4 meses. '”

Se a tônica de tais matérias é, até certo ponto, apocalíptica - em alusão ao esquema usado por Umberto Eco nos anos 1970 -, outras tratam o assunto com certa leveza, como a crônica "O feiticeiro do iPad", de Cristóvão Tezza, reconhecendo que "a onipresença da comunicação digital deve nos afetar em todas as esferas. ". Outra psicóloga, em uma das colunas citadas anteriormente, observa: “Trata-se apenas do medo natural e repetitivo que a humanidade sempre sente em relação aos avanços tecnológicos. De qualquer forma, e com as informações disponíveis, não há alternativa a não ser administrar esse problema com nossos filhos e com nós mesmos. ". O fato é que a complexidade da discussão não se resume à lógica do "isso ou aquilo", pois não há uma resposta válida para todos os contextos e situações.

Diversas pesquisas recentes (BUCKINGHAM, 2010; LIVINGSTONE, 2017; RIVOLTELLA, 2017; RIPAMONTI, 2016; FANTIN; GIRARDELLO, 2019) têm ponderado aspectos que precisam ser levados em consideração quando se fala da relação entre crianças, tecnologias digitais e suas mediações. Tais aspectos vão desde os políticos, sociais, econômicos e culturais - que dizem respeito a dimensões de acesso, inclusão digital, consumos, possibilidades de autoria, participação e cidadania - até os educativos, pedagógicos, éticos, estéticos e ligados à subjetividade na formação humana. Afinal, nem sempre os receios diante dos riscos das tecnologias digitais e da web significam a capacidade de educar, como diz Rivoltella (2017).

O desafio de buscar argumentos que possam contribuir com o debate, indo além da simplificação, leva-nos a considerar (e também a tensionar) o contundente Manifesto "A criança e as telas", de Serge Tisseron, publicado pela Academia de Ciências Francesa em 2013, o qual responsabiliza a todos nós pelo problema, tanto instituições quanto sociedade civil. O autor dirige-se a familiares, professores e educadores para discutir quando e como permitir e/ou introduzir as telas na vida das crianças. Tisseron sintetiza quatro pontos no manifesto: "Antes dos 3 anos, evitar as telas; não permitir o uso de console e tablet pessoais antes dos 6 anos; Internet após os 9 anos; redes sociais após os 12 anos" (TISSERON, 2013, tradução nossa).

Embora tal contribuição possa ser considerada "etapista", o autor destaca que as idades sugeridas são apenas pontos de partida para a discussão e que o principal é que haja negociação nas escolhas, acompanhamento das descobertas na Internet e mediação na navegação das crianças. Consciente da complexidade que envolve a questão, Tisseron esclarece que "os usos excessivos e problemáticos das telas não são apenas uma causa de possíveis problemas, são também a consequência de dificuldades enfrentadas cotidianamente" (2016, p. 16, tradução nossa). De qualquer modo, se, por um lado, suas afirmações sustentam-se em pesquisas, por outro, suas indicações operativas necessitam ser reconduzidas às singularidades dos contextos e às especificidades das crianças.

Nesse sentido, as indicações educativas propostas por Tisseron seguem três direções: a Autorregulação, a Alternância, e o Acompanhamento. Esses “3 A”, lembra Rivoltella (TISSERON, 2016), envolvem preocupações clássicas da mídia-educação, que visam desenvolver tanto o empoderamento dos sujeitos, para que lidem criticamente com mídias e tecnologias, quanto a apropriação dos artefatos digitais, como oportunidade de aprendizagem e desenvolvimento.

Se estudos anteriores sugeriam o uso compartilhado e os limites de tempo e conteúdo, ao lado da restrição técnica, do monitoramento e da proibição (LIVINGSTONE; HELSPER, 2008), a mediação como 
negociação, a partir da Autorregulação, da Alternância e do Acompanhamento, na perspectiva da mídiaeducação, avança tal compreensão. Além disso, pode dialogar com as vertentes da mediação educativa sugeridas por Livingstone (2017): mediação capacitadora (a conversa, o encorajamento, o aconselhamento) e mediação restritiva (a insistência, a proibição, a restrição desinformada), numa vertente que parece válida para diferentes contextos da formação.

Ao discutir o papel da escola e de outras instituições públicas, Tisseron destaca o papel da educação voltada à dimensão digital desde a infância. Ou seja, a importância de aprender a "fazer de conta", nos espaços lúdicos de simulação do mundo digital (de 3 a 6 anos); a lógica das telas, seus efeitos, armadilhas, riscos e possibilidades; os direitos e deveres na Internet; e aspectos dos modelos informáticos e econômicos das redes e da identidade digital (6 e 9 anos); as identidades múltiplas e plurais; o trabalho coletivo e o pensamento colaborativo; a passagem da aprendizagem intuitiva à sua explicitação; e o encorajar e valorizar as práticas de criação com as tecnologias digitais por meio de uma nova cultura de imagem on-line e da produção digital (após os 12 anos). O autor destaca que, em todas as fases, é preciso lembrar dos interesses de mercado e dos mecanismos de controle dos dados pessoais, o que implica um olhar crítico para as diferentes formas de consumo e de propostas pedagógicas. Conclui enfatizando o papel da mediação adulta no processo: "seria inaceitável que as crianças hoje com 3 anos devessem aprender sozinhas a apropriar-se das telas, exatamente como fez a maioria dos adolescentes de hoje, a seu risco e perigo" (TISSERON, 2016, p. 133).

O isolamento das crianças nos espaços domésticos, provocado pela crise sanitária de 2020, tornou ainda mais dramática a ausência dessa educação para o digital, a começar pela desigualdade no acesso às tecnologias. Não só as escolas e os educadores tiveram que propor soluções pedagógicas precárias e de última hora - já que raramente possuíam qualquer formação específica para educar com as mídias -, como também, de modo geral, as famílias não tinham referências para uma mediação adulta adequada ao uso das telas. Assim, a urgência de que tais temas sejam discutidos de maneira consistente e sistemática, voltada a orientar políticas públicas, ficou ainda mais evidente. O mesmo se poderá dizer das outras duas questões polêmicas apresentadas a seguir.

\section{Urgência Renovada da Dimensão Crítica}

Um segundo tema desafiador, tanto no debate social como na pesquisa, é a urgência renovada da dimensão crítica na formação das crianças para sua relação com as mídias. A intensidade com que as crianças hoje se dedicam a criação e publicação de fotos, vídeos, blogs, memes e outros gêneros textuais é um aspecto central da infância contemporânea, protegido pelo direito das crianças à participação na cultura. Todavia, se, de um lado, celebramos o protagonismo infantil e a vitalidade criadora que a Internet favorece, isso não significa, de outro, abrir mão de nossa responsabilidade, como adultos, de buscar "garantir que cada criança seja socializada nos padrões éticos emergentes que são necessários para moldar as suas práticas como produtores de mídia e participantes em comunidades on-line" (JENKINS et al., 2006). Afinal, as estratégias discursivas de manipulação das mensagens a serviço da intolerância e do ódio são uma preocupação crescente, já que, no Brasil, por exemplo, "quatro em cada dez crianças e adolescentes usuários de Internet (40\%) declararam ter visto alguém ser discriminado na Internet nos 12 meses anteriores” (TIC..., 2016, p. 155).

Se a análise crítica dos meios de comunicação marcou os primórdios da mídia-educação no Brasil, ainda nos anos 1960 e sob a influência da obra seminal de Paulo Freire, essa ênfase perdeu força nas últimas décadas, diante de uma certa euforia da sociedade com as possibilidades de criação na cultura do compartilhamento. A partir dos anos 1990, os estudos de recepção na Comunicação, aliados aos Estudos 
da Infância, de base sociológica, generalizaram a noção de que as crianças não são receptoras passivas, mas agentes criativos em sua relação com as mídias. A partir disso, apostava-se no quanto elas, ao produzir vídeos, notícias, programas de rádio, perceberiam que os textos midiáticos não são dados naturais, mas construções de indivíduos e instituições, que têm suas próprias agendas comerciais, políticas ou ideológicas. Considerava-se que esse processo as levaria a uma criticidade maior do que se fossem simplesmente ensinadas a detectar os valores "subjacentes aos textos".

Esses pressupostos seguem válidos, bem como a noção de que é frágil um ensino que se pretenda crítico, mas que não vá além da memorização de clichês politicamente corretos. Entretanto, a radical transformação nos ambientes comunicativos, na última década, principalmente com o advento das redes sociais digitais, atravessadas de forma avassaladora por ondas de propaganda e desinformação deliberada em massa (fake news), exige a retomada de uma mídia-educação mais atenta à dimensão crítica. Isso precisa se dar em novas bases, mais horizontais e menos prescritivas, mas, ao mesmo tempo, capazes de enfrentar um cenário ainda mais adverso, diante do monopólio dos impérios digitais, da polarização e dos retrocessos conservadores que hoje marcam a vida social em países como o nosso. Tal preocupação tem sido expressa também em iniciativas da sociedade civil, como o Manifesto em Defesa da Verdade, contra a Desinformação e pela Democracia, lançado em 2019 por associações de jornalistas, juristas e acadêmicos, que salientam o papel da educação para a mídia, considerado hoje mais urgente do que nunca ${ }^{10}$.

Os "aspectos-chave" que baseavam a mídia-educação desde os anos 1990 - linguagem, produção, representação e audiência - permanecem hoje aplicáveis também à formação crítica para as redes sociais digitais (BUCKINGHAM, 2018). Ou seja, precisamos continuar a questionar as linguagens usadas nessas mídias, suas instituições e estratégias econômicas, os modos como pessoas e grupos são ali representados e como as pessoas se relacionam com as mídias, "hoje mais como usuárias do que como audiências" (BUCKINGHAM, 2018, p. 10). Contudo, talvez tenhamos que fazê-lo de forma ainda mais vigorosa. O recente ímpeto de iniciativas voltadas à desinformação generalizada, apoiadas por recursos computacionais, comerciais e políticos de diferentes ordens, parece exigir dos educadores - e das políticas educacionais - ações mais radicais e talvez mais imediatistas para evitar que as crianças se transformem elas mesmas em vetores de deseducação anticidadã.

É dessa preocupação que surgem, no debate social, orientações, por exemplo, sobre como lidar com o problema das fake news, a começar pela "regra de ouro": "Na dúvida, não compartilhe!" Em diferentes reportagens, sugere-se, por exemplo, ensinar às crianças a verificar certas pistas. O texto da informação tem exageros? Tem autor, fonte e data? Está circulando em outras mídias? Há sinais evidentes de manipulação de imagens e áudios? Sugere-se também que "todos os educadores [se tornem] checadores de fatos e repassem a seus alunos técnicas básicas de verificação” (SCOFIELD JR., 2019). Esse é um conhecimento que não está nos currículos e que não fez parte da formação de educadores, mas que é preciso aprender, muitas vezes junto com as próprias crianças.

Tal abordagem, mais imediatista ou paliativa, embora necessária, precisa também levar em conta que "uma mídia-educação crítica adequada aos atuais desafios é necessariamente interdisciplinar" (BULGER; DAVISON, 2018). Isso nos leva a buscar referências não só no campo da Educação, mas também em campos vizinhos, como o da Comunicação, no qual pesquisas apontam o papel dos algoritmos de visibilidade das ferramentas que "selecionam o que será visto pelos atores com base em suas próprias ações e nas ações de sua rede social” (RECUERO; GRUZD, 2019). Um trabalho mídia-educativo focado nesse tema estaria ligado ao aspecto-chave "produção", que tradicionalmente inclui questionamentos sobre circulação e distribuição: "Como os textos alcançam suas audiências? Qual a escolha e o controle de que o público dispõe?” (BUCKINGHAM, 2003 , p. 54). Para atualizar essa discussão, e mesmo sem entrar em detalhes de teoria computacional junto às 
crianças, podem ser feitas experiências simples, como testar junto com elas o que acontece depois que buscam no Google determinados temas e, em consequência disso, passam a ver aparecerem "espontaneamente" publicações com assuntos afins, inclusive anúncios, em seus ambientes on-line.

Outro aspecto-chave tradicional na mídia-educação, "representação", também requer adaptações para o novo cenário. Permanece válida a busca por problematizar a objetividade, a tendenciosidade e a estereotipia nas mensagens, a partir de questões como: "Quem fala e quem é silenciado?”; “Como as mídias representam grupos sociais específicos?” (BUCKINGHAM, 2003, p. 58). Entretanto, se, no contexto em que a mídia-educação surgiu, "as mídias" eram basicamente as grandes empresas comerciais de difusão de conteúdos, tais como emissoras de televisão, jornais e revistas, hoje, o cenário é muito mais complexo. As crianças precisam aprender, por exemplo, que, às vezes, os autores das postagens nas redes sociais nem são indivíduos, nem empresas identificáveis, mas redes de robôs ou perfis falsos, criados para intensificar a proliferação dos discursos, dando a ilusão de consensos que aumentam o extremismo e a polarização. Nesse sentido, realizar junto com as crianças exercícios de leitura atenta de comentários em canais e jornais on-line, por exemplo, pode motivar discussões enriquecedoras sobre a ação de disparos automáticos de mensagens, promovendo um saudável ceticismo diante das informações recebidas, o que é condição favorável a uma postura crítica.

Algumas pesquisas educacionais nesse sentido começam a ser feitas no Brasil, mas ainda há muito chão a percorrer. Será fundamental que as pesquisas possam aprofundar os desdobramentos da pandemia nas reconfigurações das relações entre crianças, família, escola e mídia, por exemplo, nas relações familiares (entre adultos e crianças); nos usos das tecnologias nos espaços e tempos domésticos; e nas relações entre família e escola, evidenciando outras formas de corresponsabilidade educativa a partir dos usos das tecnologias, visto que elas têm oferecido, neste 2020, condição de viabilizar (ou não) a educação escolar. Nessas relações, o papel das mídias e, particularmente, da imprensa profissional tem sido muito relevante, tanto no sentido de informar a população sobre a pandemia, dada a quase omissão e a postura negacionista do governo a esse respeito, quanto no sentido de esclarecer as notícias falsas. Nesse sentido, também enfatizamos a importância das mídias, em geral, e das redes sociais, em particular, para aproximar crianças e adultos, nos diferentes contextos que compõem os cenários da mídia-educação.

\section{Lugar do Corpo das Crianças na Cultura Digital}

Um terceiro tema inquietante refere-se ao lugar do corpo das crianças na cultura digital. Na mídia, no senso comum e mesmo no campo científico, disseminam-se discursos que abordam as relações das crianças com a mídia e as tecnologias digitais a partir do paradigma dualista cartesiano que separa o sujeito em corpo e mente, submetendo o primeiro (a natureza) aos desígnios do segundo (a razão). Esses discursos abordam, por exemplo, a preocupação biomédica com o corpo sedentário das crianças e com os riscos da "formação social da mente" de crianças que crescem em um isolamento promovido pelas telas. A marginalidade do corpo nos estudos de infâncias e mídias faz aflorar a dificuldade que temos, na sociedade em geral e também no campo da educação, de considerar crianças como corpos sensíveis e expressivos, além da dificuldade de enfrentar questões expressas e impressas no corpo, como gênero, sexualidade, etnia, sexting, padrões de beleza, bullying, entre outras.

Alertados por Buckingham (2003) de que visões deterministas da tecnologia (sejam apocalípticas ou apologéticas) desembocam em visões essencialistas de infância (sob o risco de que as crianças sejam alienadas de seus corpos), buscamos construir, em diálogo com outros dois manifestos - reflexões sobre a importância de considerarmos que as crianças são sempre corpo no mundo, inclusive em suas relações com 
a mídia. Propomos, assim, um olhar para as crianças que considere que a nossa existência - ser-no-mundo - só é possível como corpo: um corpo sócio-histórico, dialógico, que percebe e expressa por ser sensível e motriz (MERLEAU-PONTY, 1980).

No primeiro documento, intitulado Manifesto da Criança Digital, a pesquisadora do Instituto de Tecnologia de Massachusetts (MIT), Edith Ackermann, evoca a voz das crianças para reivindicar que não nos esqueçamos de seus corpos: “[...] por favor, não esqueçam que eu tenho um corpo e gosto de usá-lo. Deixem-me liberar minha imaginação, transportem-me, teletransportem-me, mas também me deixem tocar, sentir, movimentar-me, ter um chão sólido debaixo dos pés" (ACKERMANN, 2013, p. 131).

O não esquecimento da dimensão corporal das crianças, por um lado, destaca a importância de que elas possam viver seus corpos como espaço eminentemente expressivo (PEREIRA, 2014). O corpo, ser sensível e motriz, projeta-se no mundo ao mesmo tempo que o incorpora e é nesse encontro dialógico - com o mundo, com os outros e consigo -que a criança se constitui humana. Para Merleau-Ponty (1999, p. 540), o sentido das palavras não se dá como tomada de consciência, mas como experiência encarnada: para aprender a ler a palavra, já nos disse Paulo Freire (1989), é preciso antes aprender a ler o mundo. A palavramundo freireana (FREIRE, 1989), fruto de uma leitura crítica que percebe as relações entre texto e contexto, palavra e mundo, constitui-se no brincar de um corpo que sente e se expressa entre espaços, formas, texturas, cores, cheiros, histórias, imagens, músicas, gestos - sejam ou não digitais. Por outro lado, o digital e suas múltiplas linguagens, inseparáveis do fluxo da vida, não envolvem as crianças apenas em pensamento, mas na totalidade corporal que elas são (PEREIRA, 2014).

Já o Manifesto OnLife é uma iniciativa coordenada pelo filósofo italiano Luciano Floridi (2015). Ao propor o neologismo "OnLife", o documento defende que nem sempre a base conceitual moderna tem sido capaz de nos ajudar a compreender os impactos das tecnologias digitais na sociedade e a formular políticas para enfrentar os desafios de uma era hiperconectada. Assim, o manifesto aponta que as seguintes transformações foram impulsionadas pelas tecnologias digitais: o embaçamento das fronteiras entre real e virtual, assim como o das fronteiras entre humano, natureza e máquina; a inversão de um cenário de escassez de informação para um de abundância de informação; e o deslocamento da primazia das entidades para a primazia das interações.

Uma das mudanças conceituais centrais ao Manifesto OnLife converge com o Manifesto da Criança Digital: a concepção ocidental moderna de sujeito - um "eu" individual, racional e sem corpo -não é capaz de explicar o modo como estamos produzindo "OnLife" nossas identidades, relações, consumos, políticas - enfim, nossos modos de vida. Como alternativa, propõe-se outro projeto de racionalidade, ancorado na concepção fenomenológica de que somos corpos-sujeito relacionais.

O entrecruzamento do contexto "OnLife" com o corpo das crianças ganhou novos contornos com a necessidade de isolamento social decorrente da crise sanitária de 2020. Em um primeiro olhar, evidencia-se a inegável limitação que o confinamento impôs às possibilidades de movimento das crianças, em especial àquelas que têm nas instituições escolares o principal - quando não o único - lugar para brincadeiras de movimento que envolvam espaços mais amplos e interação com seus pares. Por sua vez, as escolas em ensino remoto perderam o corpo das crianças e, com ele, estratégias de controle e disciplinamento (BASSANI; VAZ, 2012). Nesse cenário, a compreensão de que a criança é um corpo-sujeito relacional nos auxilia a reconhecer e potencializar caminhos para aprender e interagir. Nessa direção, em uma relação com o que propõe Serge Tisseron em seu manifesto, mencionado no primeiro item, a brincadeira com e através das mídias é também um espaço de manifestação do corpo: o olhar da criança envolve e apalpa o que vê (MERLEAU-PONTY, 1992, p. 131); a criança que brinca a partir dos suportes digitais se projeta corporalmente na tela e, ao mesmo tempo, incorpora aquilo que vivencia, transpõe enredos e saberes para outras manifestações do seu brincar, muitas dessas repletas de movimento (MUNARIM, 2007). 
Para enfrentar os problemas apontados nesses manifestos e pensar o lugar do corpo na relação entre infâncias e mídias, especificamente na educação, nossa principal referência é a perspectiva dos multiletramentos (COPE; KALANTZIS, 2009; 2016; PEREIRA, 2014). Fruto de um projeto internacional que busca considerar os desafios para o ensino do letramento em um mundo que enfrenta grandes transformações, a proposta dos multiletramentos sugere que representações multimodais da linguagem, potencializadas e mixadas nas mídias e tecnologias digitais, sejam inseridas em sala de aula e façam parte das produções de sentido e aprendizagens das crianças. Ao entrecruzar diferentes tipos de linguagem (sons, escritas, texturas, imagens, movimentos corporais), expressos em diferentes meios (do gesto à Internet), a proposta dos multiletramentos anuncia em seu horizonte tornar-se uma pedagogia da sinestesia. Considerada - numa perspectiva fenomenológica (MERLEAU-PONTY, 1999) - uma interconexão de sentidos que tem no corpo o ponto de encontro do sujeito com o mundo, a sinestesia abre caminhos para pensarmos sobre como compreender, respeitar e potencializar o protagonismo de crianças que caminham com a imaginação e os pés sobre chãos de terra e de bits, muitas vezes ao mesmo tempo.

Se considerarmos que as crianças são corpos que se relacionam sinestesicamente com o mundo, os processos formativos atentos aos multiletramentos podem incorporar diálogos entre/em diferentes linguagens e suportes. A multiplicidade de linguagens se expressaria, assim, pela "capacidade de transitar por elas, de traduzi-las, misturá-las, mixá-las. Fazer da palavra, gesto. Do movimento, som. Da escrita, sensações. Da vida, arte" (PEREIRA, 2014, p. 62).

Em suma, sinalizamos aqui três polêmicas contemporâneas que, a nosso ver, precisam ser enfrentadas para qualificar o debate e a pesquisa no campo das relações entre as crianças e as mídias. Sugerimos, também, a atualização de algumas perspectivas teórico-metodológicas que nos parecem úteis para abordar essas polêmicas. O desafio de criar ambientes em que as crianças possam viver e se desenvolver em uma infância saudável, que já era grande antes de 2020, parece ter se agigantado ao longo da pandemia, que está em pleno andamento no momento da escrita este artigo. Se, na educação brasileira, ainda estamos bastante atordoados em meio à incerteza sobre os cenários futuros, avaliamos que os temas e debates apontados aqui já provocaram um acúmulo teórico importante, que pode ser ainda mais necessário para orientar decisões político-pedagógicas. Assim, entre riscos e potencialidades, reafirmamos uma concepção de mídia-educação que promova o uso crítico, criativo e responsável das mídias e tecnologias disponíveis, atenta à necessidade corpórea e imaginativa que a criança tem de brincar, em uma mediação adulta sensível e bem-informada. Movemo-nos por um sentimento de urgência, mas também pela compreensão do quanto a atenção criteriosa, o aprofundamento reflexivo e o diálogo interdisciplinar são imprescindíveis para intervir nos desafios inéditos com que deparam os pesquisadores e educadores preocupados com a saúde e a felicidade das crianças de nosso tempo.

\section{Contribuições dos Autores}

Conceptualização: Girardello G, Fantin M, Pereira RS; Metodologia: Girardello G, Fantin M, Pereira RS; Redação: Girardello G, Fantin M, Pereira RS.

\section{Notas}

1. Disponível em: http://brasil.elpais.com/brasil/2017/02/24/tecnologia/1487959523_030409.html. Acesso em: 19 set. 2020.

2. Disponível em: https://brasil.elpais.com/brasil/2017/12/12/tecnologia/1513075489_563661.html. Acesso em: 19 set. 2020. 
3. Disponível em: https://brasil.elpais.com/brasil/2018/05/24/tecnologia/1527154323_038822.html. Acesso em: 19 set. 2020.

4. Disponível em: https://brasil.elpais.com/brasil/2018/01/23/tecnologia/1516666969_215422.html. Acesso em: 19 set. 2020.

5. Disponível em: http://emais.estadao.com.br/blogs/ser-mae/estamos-criando-uma-geracao-de-alienados-afirma-psicologodo-hc/. Acesso em: 19 set. 2020.

6. Disponível em: https://brasil.elpais.com/brasil/2018/12/28/opinion/1545984716_407266.html. Acesso em: 19 set. 2020.

7. Disponível em: https://brasil.elpais.com/brasil/2019/03/20/actualidad/1553105010_527764.html. Acesso em: 19 set. 2020.

8. Disponível em: https://www1.folha.uol.com.br/colunas/cristovao-tezza/2018/09/o-feiticeiro-do-ipad.shtml. Acesso em: 19 set. 2020.

9. Disponível em: https://brasil.elpais.com/brasil/2018/12/28/opinion/1545984716_407266.html. Acesso em: 19 set. 2020.

10. Disponível em: https://www.brasildefato.com.br/2019/06/06/painel-combate-as-fake-news-luta-contra-a-desinformacao-epela-educacao-para-midia/. Acesso em: 19 set. 2020.

\section{REFERÊNCIAS}

ACKERMANN, E. K. Growing up in the digital age: Areas of change. Tecnologias, Sociedade e Conhecimento, Campinas, v. 1, n. 1, nov. 2013.

BASSANI, J. J.; VAZ, A. F. Sobre a cisão entre sujeito e objeto, segundo Theodor W. Adorno: Questões para a educação do corpo. Educação e Filosofia, Uberlândia, v. 26, n. 52, p. 641-671, 30 dez. 2012. https://doi. org/10.14393/REVEDFIL.issn.0102-6801.v26n52a2013-p641a671

BUCKINGHAM, D. Media Education: Literacy, learning and contemporary culture. Cambridge: Polity Press, 2003.

BUCKINGHAM, D. Do we really need Media Education 2.0? In; DROTNER, K.; SCHRODER, K. Digital content creation. Perception, practices \& perspectives. New York: Peter Lang, 2010.

BUCKINGHAM, D. Going critical: On the problems and the necessity of media criticism. In: David Buckingham Files, [s. l.], 2018. Disponível em: https://ddbuckingham.files.wordpress.com/2018/07/goingcritical.pdf. Acesso em: 19 set. 2020.

BULGER, M.; DAVISON, P. The promises, challenges and futures of media literacy. Journal of Media Literacy Education, Cherry Hill, v. 10, n. 1, p. 1-21, 2018. Disponível em: https://digitalcommons.uri.edu/jmle/vol10/ iss1/1/. Acesso em: 19 set. 2020. https://doi.org/10.23860/JMLE-2018-10-1-1

COPE, B.; KALANTZIS, M. “Multiliteracies”: New literacies, new learning. Pedagogies, Mahwah, v. 4, n. 3, p. 164-195, 2009. https://doi.org/10.1080/15544800903076044

COPE, B.; KALANTZIS, M. (orgs.). A pedagogy of multiliteracies: Learning by design. Basingstoke: Springer, 2016. 
FANTIN, M. TISSERON, Serge. 3-6-9-12 Diventare grande all'epoca degli schermi digitali. Brescia: La Scuola, 2016 (153p). Entreideias, Salvador, v. 5, n. 1, p. 123-127, jan.-jun. 2016. https://doi.org/10.9771/2317-1219rf. v5i1.16754

FANTIN, M. Crianças, dispositivos móveis e aprendizagens formais e informais. ETD - Educação Temática Digital, Campinas, v. 20, n. 1, p. 66-80, 2018. https://doi.org/10.20396/etd.v20i1.8647545

FANTIN, M.; GIRARDELLO, G. Cenários de pesquisa com e sobre criança, mídia, imagens e corporeidades. Perspectiva, Florianópolis, v. 37, n. 1, p. 100-124, jan.-mar. 2019. https://doi.org/10.5007/2175-795X.2019.e54575

FLORIDI, L. (org.). The OnLife manifesto: Being human in a hyperconnected era. |Cham; Springer International Publishing, 2015. Disponível em: https://link.springer.com/book/10.1007/978-3-319-040936. Acesso em: 19 set. 2020.

FREIRE, P. A importância do ato de ler: Em três artigos que se completam. São Paulo: Autores Associados/ Cortez, 1989.

JENKINS, H. et al. Confronting the challenges of participatory culture: Media education for the 21st century. Chicago: MacArthur Foundation, 2006.

LIVINGSTONE, S. Digital skills matter in the quest for the 'holy grail'. In: LONDON SCHOOL OF ECONOMICS. Parenting for a Digital Future, [s. l.], Feb. 2017. Disponível em: https://blogs.lse.ac.uk/ parenting4digitalfuture/2017/02/07/digital-skills-matter-in-the-quest-for-the-holy-grail/. Acesso em: 19 set. 2020.

LIVINGSTONE, S.; HELSPER, E. Parental mediation and children's Internet use. Journal of Broadcasting \& Electronic Media, Washington, v. 52, n. 4, p. 581-599, 2008. https://doi.org/10.1080/08838150802437396

MERLEAU-PONTY, M. O olho e o espírito. Textos escolhidos: Maurice Merleau-Ponty. São Paulo: Abril Cultural, 1980, p. 85-111.

MERLEAU-PONTY, M. O visível e o invisível. São Paulo: Perspectiva, 1992.

MERLEAU-PONTY, M. Fenomenologia da percepção. Trad. Carlos Alberto Ribeiro de Moura. 2. ed. São Paulo: Martins Fontes, 1999.

MUNARIM, I. Brincando na escola: O imaginário midiático na cultura de movimento das crianças. 2007. Dissertação (Mestrado em Educação) - Programa de Pós-graduação em Educação, Universidade Federal de Santa Catarina, Florianópolis, 2007. Disponível em: https://repositorio.ufsc.br/xmlui/ handle/123456789/89776. Acesso em: 19 set. 2020

PEREIRA, R. S. Multiletramentos, tecnologias digitais e os lugares do corpo na educação. 2014. Tese (Doutorado em Educação) - Programa de Pós-graduação em Educação, Universidade Federal de Santa Catarina, Florianópolis, 2014. Disponível em: https://repositorio.ufsc.br/xmlui/handle/123456789/123332. Acesso em: 19 set. 2020. 
RECUERO, R.; GRUZD, A. Cascatas de fake news políticas: Um estudo de caso no Twitter. Galáxia, São Paulo, n. 41, p. 31-47, ago. 2019. https://doi.org/10.1590/1982-25542019239035

RIPAMONTI, D. Bambini e tecnologie digitali: Opportunità, rischi e prospettive di ricerca. Media Education, Moskva, v. 7, n. 2, p. 143-157, 2016. https://doi.org/10.14605/MED721601

RIVOLTELLA, P. C. Tecnologie di Comunità. Brescia: La Scuola, 2017.

TIC KIDS ONLINE BRASIL. Pesquisa sobre o uso da Internet por crianças e adolescentes no Brasil. São Paulo: Comitê Gestor da Internet no Brasil, 2016.

TISSERON, S. 3-6-9-12. Apprivoiser les écrans et grandir. Toulouse: Éditions Érés, 2013. Disponível em: https://www.3-6-9-12.org. Acesso em: 19 set. 2020.

TISSERON, S. 3-6-9-12. Diventare grandi allepoca degli schermi digitali. Brescia: La Scuola, 2016.

SCOFIELD JR., G. Uma educação necessária: Checadores e professores juntos contra as fake news. Folha de São Paulo, São Paulo, 02 abr. 2019. Opinião. Disponível em: https://www1.folha.uol.com.br/opiniao/2019/04/ uma-educacao necessaria.shtml. Acesso em: 19 set. 2020.

Recebido: 06 Jan. 2020

Aceito: 10 Jul. 2020

Editoras Associadas:

Adriana Laplane e Lucia Reily 